\title{
LAS TRANSICIONES DE LOS JÓVENES: UN ESPACIO ENTRE LAFAMILIA Y LA AUTONOMÍA DE VIDA. CONSECUENCIAS PARA EL TRABAJO SOCIAL
}

\section{JESÚS HERNÁNDEZ ARISTU}

Profesor y Doctor Dpto. de Trabajo Social. Universidad Pública de Navarra. ANDREU LÓPEZ BLASCO

Doctor. Sociólogo.

\section{INTRODUCCIÓN}

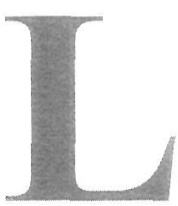

a familia constituye un colchón y un refugio contra la adversidad y la crisis", leímos en el quinto informe sobre la situación social en España de la Fundación Foessa, (Documentación Social 1995 n $^{\circ}$ 101, pag.156). En un estudio realizado recientemente en Navarra (Véase HernándezAristu / López Blasco 2001) constatábamos una vez más que la familia viene prestando servicios a sus miembros que en otros países de nuestro entorno social y político son propios del Estado Bienestar. Sin el apoyo de los abuelos y abuelas muchas madres, -más que padres- no podrían seguir con su carrera profesional adelante. Sin las mujeres mayores de 45 años sería igualmente imposible mantener la atención de los miembros mayores, enfermos o dependientes de la familia. También es importante la aportación de las familias en el ámbito educativo. No sólo es un agente de socialización fundamental, sino que se ocupa tanto de las actividades escolares como de las extraescolares.

Pero la afirmación de que sin la familia, los jóvenes o hubieran tenido una peor situación, más dramática o se hubieran revelado contra una sociedad que les abre las puertas de la educación y de la formación (por lo menos hasta ahora y hasta un determinado nivel, la escuela obligatoria) y les cierra las puertas al empleo, es especialmente certera. La familia se ha convertido en los años de la transición española y posteriormente hasta nuestros días en el lugar en el que y desde el que los jóvenes esperan a dar el salto a una situación de estabilidad profesional y laboral que les permita seguir la vida con una cierta normalidad, es decir, pudiendo asumir ciertas responsabilidades sociales, laborales y en su caso políticas, y sobre todo su propia vida en sus manos, 
independientemente de sus padres y madres.

Mientras esperan los jóvenes, las familias españolas se han convertido en el soporte de los jóvenes por un lado y por otro y de paso en el amortiguador de las (posibles) revueltas sociales. La cuestión que se presenta es: ¿durante cuánto tiempo podrán las familias españolas seguir cumpliendo con esta función? La pregunta alcanza especial relevancia teniendo en cuenta las grandes trasformaciones que venimos igualmente observando en ella: una bajada drástica de las tasas de natalidad, de las más bajas de toda Europa, un avance significativo de la emancipación de la mujer, sin bien todavía en proceso de crecimiento, el aumento de las familias monoparentales, la tasas de nacimientos fuera de matrimonio, el divorcio y los nuevos casamientos o emparejamientos con hijos o sin ellos de otros anteriores matrimonios etc. $y$, por último, el proceso de individualización que observamos en toda la sociedad, en la que las personas deben asumir su propia responsabilidad al margen de normas sociales, tradiciones y valoraciones comunes.

No se trata sólo de interrogantes sobre la familia, sino sobre todo y en este contexto sobre la necesidad de dar respuestas y apoyos a las funciones que por una u otra razón han venido cumpliendo en relación a las nuevas generaciones o por la asunción directa de estas funciones por parte del estado de bienestar, descargando a las familias de las mismas, como lo ha hecho, aunque sea con deficiencias en el ámbito de la educación y de la sanidad, por ejemplo.

Pérez-Díaz (1998) lo resume muy bien cuando afirma: "resulta interesante observar cómo la familia española ha realizado y realiza aportaciones al tiempo que recibe muy pocos apoyos directos del estado, al tiempo que está sometida a transformaciones importantes que, aparentemente, arrojan dudas sobre su capacidad para autoreproducirse y seguir así desempeñando en el futuro las funciones que hoy cumple, y al tiempo que está desplazando una parte desproporcionada de la responsabilidad por estas funciones a los miembros femeninos de la familia" (p. 169).

Para el ejercicio de las profesiones de ayuda, como la del trabajador/a social se plantea la cuestión de qué funciones surgen del análisis de esta situación para los servicios sociales, y dentro de ellos para los trabajadores/as sociales. ¿A qué deben estar atentos, cuáles son los problemas que emanan de la misma en nuestro caso para los jóvenes, qué tipo de apoyos sociales debemos poner en marcha o reforzar para alcanzar transiciones exitosas de los jóvenes?, ¿cuáles son los problemas a los que se enfrentan las familias en general y más concretamente las familias menos dotadas, con mayores dificultades de integración? 


\section{EL CONCEPTO DE TRANSICIÓN}

El concepto "transición" se viene utilizando desde los años setenta para investigar, analizar el paso de los/las jóvenes de la escuela al mercado laboral o también se ha usado para describir el paso de la juventud a la vida adulta. Se utiliza para valorar si la transición ha resultado o no exitosa, o qué elementos influyen o han impedido el paso de un estatus al otro.

En los estudios de evaluación de las medidas cofinanciadas por el Fondo Social Europeo, que el equipo INSONA ${ }^{1}$ del Departamento de Trabajo Social de la Universidad Pública llevó a cabo en Navarra, desde 1994 al 2000 al igual que en los estudios e investigaciones nacionales e internacionales, hemos venido observando que ya no podemos hablar refiriéndonos a la juventud, sin más, de transición, sino más bien de transiciones, dado que los/las jóvenes ni todos hacen el mismo itinerario de paso a la edad adulta, ni muchos lo hacen de una vez, sino que lo hacen por decirlo de alguna menara, por "entregas" y otras suelen hacerlo a trompicones, avanzando y retrocediendo de una posición de, por ejemplo, empleo, a otra de desempleo, de vivir independientemente de la familia y de volver de nuevo al seno familiar. También hemos utilizado para expresar esta situación el concepto de reversibilidad: los ritos de pasaje, de cambio de estatus, no son ni lineales, ni definitivos.

Los umbrales tradicionales de transición a la vida adulta -abandono de la familia de origen, matrimonio, obtención de trabajo-son reversibles. Los polos opuestos estudiante/no estudiante, activo/inactivo, soltero/ casado, están interpuestos entre una multiplicidad de estatus intermedios y reversibles más o menos transitorios o precarios.

Las mismas secuencias de esos umbrales de paso no son lineales o uniformes; el abandono de la familia de origen no siempre coincide con el final de la escolaridad o incluso con el matrimonio; la obtención de experiencia profesional puede tener lugar en la fase de estudiante; la cohabitación puede ser anterior a la obtención de empleo estable. La adquisición de un empleo no lleva necesariamente al abandono del domicilio paterno-materno. En definitiva, los procesos de transición son

INSONA responde al nombre del equipo de investigación de Investigaciones Sociales Navarra, del Departamento de Trabajo Social de la Universidad Pública de Navarra, coordinado y dirigido por los autores de este artículo, que viene realizando sus investigaciones en ámbitos como el de la evaluación de programas de formación ocupacional, la elección de profesiones, la educación de adultos, la familia, las transiciones de los jóvenes. También ha realizado proyectos de intervención para la formación e inserción laboral de los jóvenes desescolarizados y desempleados, en el ámbito de la mediación comunicativa entre instituciones y organizaciones. Ha publicado varios libros y artículos al respecto. Este artículo se apoya en esas investigaciones. 
francamente heterogéneos y están marcados por discontinuidades y rupturas apreciables (Machado, J. 1997).

Los jóvenes de esta generación tan pronto abandonan los estudios, consiguen trabajo y se casan -dejando de ser jóvenes y pasando a ser adultos- como, con la misma rapidez, caen nuevamente en el paro, vuelven a la condición de estudiantes, o se divorcian, redescubriendo la juventud y con frecuencia volviendo al nido familiar originario.

El principio de reversibilidad en los procesos de transición a la vida adulta hace que algunos jóvenes abandonen la escuela, ante la expectativa de iniciar una carrera profesional, para acabar volviendo a ella, dadas las dificultades que hay para conseguir trabajo. Otros se quedan en la escuela, pero se sienten de más en ella.

El principio de reversibilidad también se da en la vida familiar. Unas décadas atrás, la forma dominante correspondía al abandono de la familia de origen, con la finalidad del matrimonio. Sin embargo, hoy en día, el estar soltero parece configurar una forma importante de abandono de la familia de origen. La mayoría de los jóvenes que viven fuera de la casa paterna no deja por eso de vivir económicamente dependiente de ella.

Aunque en nuestros estudios hemos preferido hablar de proceso de socialización (véase López-Blasco, Hernández Aristu y otros, 1999) como más adecuado que el de transición o transiciones, sin embargo, este concepto nos permite en este trabajo en concreto poner de manifiesto la situación de inseguridad y dependencia en la que se encuentran los jóvenes al igual que poner de relieve la función o funciones que la familia de origen cumple respecto a los/las jóvenes y su significado para la proyección del futuro propio familiar. El trabajo social con jóvenes gana desde esta perspectiva nuevos horizontes.

\section{LA JUVENTUD MEJOR PREPARADA DE LA HISTORIA ESPAÑOLA EN ESPERA DE UNA OPORTUNIDAD LABO- RAL}

Existen dos factores que están contribuyendo al aumento del período de dependencia de los/las jóvenes y que por otra parte y hasta ahora han constituido un binomio inseparable han devenido en las sociedades postmodernas en elementos desconexionados. Nos referimos a la expansión educativa y la situación del mercado de trabajo.

La larga permanencia en las instituciones educativas también lleva consigo un aumento de las cualificaciones a través de las cohortes 
sucesivas: en la UE $1 / 3$ de los jóvenes abandona la escuela sin alcanzar el nivel de la cualificación secundaria, y comparados sin embargo con los que ahora tienen unos 50 años, los jóvenes actuales doblan a aquellos en titulaciones superiores.

El porcentaje de jóvenes entre 15 y 19 años que se encuentra escolarizado en la actualidad (año 2000) en España, es del 75,3\% frente al $67,2 \%$ registrado en 1993 . Es decir 8 puntos de diferencia en tan sólo 7 años. Lo mismo ocurre con los jóvenes entre 20-24 años, los cuales en 1993, tenían una tasa de escolarización del $36,1 \%$ frente al $45,4 \%$ actual. Los jóvenes-adultos de 25-29 años han visto también incrementada su tasa de escolarización, pasando de un 12,7\% en 1993 a un $16,8 \%$ en 2000 .

La incorporación femenina ha tenido mucho que ver en el aumento de estos índices. Según los datos obtenidos para los diferentes grupos de edad, las mujeres poseen unas tasas de escolarización mucho más elevadas que las masculinas.

\subsection{La expansión educativa es un hecho que alcanza a la mayo-} ría de los/las jóvenes

En la tabla siguiente podemos ver que la proporción de mujeres por cohorte de edad es superior a la de los hombres. Constatación que es algo más que el dato estadístico ya que tiene su influencia en el aumento de la tasa de actividad femenina, en el retraso de la edad de nupcialidad y en el índice de natalidad (dilema entre el deseo de tener hijos y el deseo de realizarse en la profesión aprendida).

Tabla 1. Tasa de escolarización según grupo de edad. Comparación 1993-2000.

\begin{tabular}{|c|c|c|c|c|}
\hline & Año & Total\% & Hombres \% & Mujeres \% \\
\hline 16-19 años & 1993 & 67,2 & 61,9 & 73,0 \\
\cline { 2 - 5 } & 2000 & 75,3 & 70,6 & 80,3 \\
\hline 20-24 años & 1993 & 36,1 & 35,7 & 45,2 \\
\cline { 2 - 5 } & 2000 & 45,4 & 40,7 & 50,3 \\
\hline \multirow{2}{*}{$25-29$ años } & 1993 & 12,7 & 12,3 & 16,6 \\
\cline { 2 - 5 } & 2000 & 16,8 & 16,0 & 17,6 \\
\hline
\end{tabular}

FUENTE: INE-Instituto Nacional de Estadística. Encuesta de Población Activa. 2000 (ler trimestre). Informe sobre España, Proyecto TSER (AREA). Junio 2000.

Las familias españolas apoyan la permanencia de sus hijos/as en el sistema educativo y apuestan por una entrada en el sistema lo antes 
posible. Somos el primer país de la Unión Europea en tener la mayor escolarización de los niños de 3 años (el 83,5\%) y de 4-5 años, con una escolarización prácticamente del 100\%.

Tabla 2. Evolución de las tasas de escolaridad según grupos de edad.

\begin{tabular}{|l|c|c|c|}
\hline & $\mathbf{1 9 8 8 - 8 9}$ & $\mathbf{1 9 9 3 - 9 4}$ & $\mathbf{1 9 9 9 - 0 0}$ \\
\hline 3 años & 18,5 & 51,8 & 83,5 \\
\hline 4-5 años & 95,1 & 98,5 & 100 \\
\hline 6-13 años & 100 & 100 & 100 \\
\hline 14-15 años & 89,1 & 96,8 & 100 \\
\hline 16-17 años & 63,8 & 74,9 & 83,5 \\
\hline 18-20 años & 40,0 & 51,5 & 61,1 \\
\hline 21-24 años & 20,0 & 26,5 & 32,9 \\
\hline 25-29 años & 4,7 & 6,2 & 7,6 \\
\hline
\end{tabular}

FUENTE: Ministerio de Educación y Ciencia. 1999. Informe sobre España, Proyecto TSER (AREA) Junio 2000.

La permanencia en las instancias educativas se enmarca también en la política educacional europea que aboga por el "longlife learning": aumenta la demanda de personal cualificado, los puestos de trabajo se concentran en el sector servicios y cada vez son más las personas cualificadas, "hipercualificadas", que se ofrecen para realizar trabajos que exigen menos cualificación que la que estas personas han adquirido.

Alta cualificación y desempleo juvenil intensifican la competencia de los/las jóvenes por los puestos de trabajo. Esta competencia por bienes escasos está originando, por un lado que los/las jóvenes tienden a ampliar sus cualificación asistiendo a cursos, masters, etc. y otras medidas de apoyo a la búsqueda de trabajo, y por otro a expulsar los mejor cualificados a personas con menos cualificación del mercado laboral.

La expansión educativa y la prolongación de los estudios y de la formación, como uno de los mejores pasaportes para el empleo, trae consigo una presión hacia abajo, que desde el punto de vista social puede crear dificultades: "los jóvenes que tienen niveles de cualificaciones inferiores se ven abocados a empleos menos cualificados que aquéllos que pensaban conseguir. Este efecto de "hacer cola" termina por afectar a los de menor titulación y a los que carecen de ella, y se convierte en un factor importante de exclusión social"(Libro Blanco, 11/p.5). Un estudio de la OCDE de 1989 y que reproduce el Club de Roma en su último informe (1998) constata una relación directa entre formación y empleo en el sentido que venimos comentando, "las perso- 
nas con menor nivel educativo suelen tener tasas de desempleo más altas -son, los que tienen una menor formación, los que sufren más en términos de desempleo-" (p. 124).

Para el trabajo social surgen desde aquí funciones importantes de cara a apoyar a los y las jóvenes con menos opciones en el ámbito de la formación. Desde iniciativas por mejorar el rendimiento escolar hasta iniciativas por apoyar a los jóvenes en la búsqueda de nuevas oportunidades de formación, completar la formación inicial, el asesoramiento profesional en la elección de los cursos, así como el apoyo psico-social en los fracasos, dudas e inseguridades se convierten en espacios propios del trabajo social, en los que trabajadores sociales no pueden inhibirse. La atención a los jóvenes en su formación escolar y profesional al igual que en el uso del tiempo libre fue uno de los orígenes de lo que hoy llamamos Trabajo Social en el siglo XIX e inicios del XX (véase Friedlander 1989, p.114 y ss.).

Con frecuencia este grupo, que en otra ocasión hemos llamado "perdedores" (Hernández Aristu y López Blasco, 1996) no aparece ni siquiera en los cursos de formación ocupacional, desaparece del mercado de trabajo. El trabajo social de calle, la búsqueda de los "escondites" de estos jóvenes, así como el apoyo en la búsqueda y mantenimiento del empleo, la búsqueda y desarrollo de "nuevas" identidades, (López Blasco y Hernández Aristu, 2001) son otras tantas áreas que no pueden ser ajenas a las inquietudes y actividades del trabajo social y de sus profesionales.

El otro factor característico de la situación de los jóvenes en España es el del desempleo y el de la precariedad laboral. La contratación suele ser temporal y por unos meses. El porcentaje de temporalidad en España es en 22 puntos superior a la media de la Unión Europea.

Veamos cuál es la situación laboral en España.

\subsection{Condicionantes laborales. Situación del mercado laboral}

Es bastante frecuente encontrar, durante la década de los noventa, infinidad de materiales que hablan de la problemática del paro como el verdadero problema de las sociedades industrializadas, presentándolo a menudo como el reto/fracaso de la sociedad del bienestar. Dentro de esta dinámica siempre se suele hacer referencia, en apartado especial, a los datos estadísticos del paro juvenil, debido sobre todo a su peso cuantitativo respecto de otros grupos de edad. Su análisis suele ser ejemplarizado como el perfecto observatorio de las desigualdades en el mercado de trabajo. 
La tasa de paro en España viene siendo doble que la del conjunto de la Unión Europea. Así, aunque la tasa de paro general en España ha disminuido de un $21,7 \%$ en 1993 a un $16,9 \%$ en 1999 , las cifras se encuentran en todo momento lejanas a las de la Unión Europea.

Tabla 3. Tasa de paro en España y en la Unión Europea. De 1993 a 1999.

\begin{tabular}{|l|r|r|r|r|}
\hline Año & $\mathbf{1 9 9 3}$ & $\mathbf{1 9 9 5}$ & $\mathbf{1 9 9 7}$ & $\mathbf{1 9 9 9}$ \\
\hline Tasa de paro en España* & 21,7 & 23,5 & 21,4 & 16,9 \\
\hline Tasa de paro en la Unión Europea*** & 10,8 & 11,0 & 10,7 & 9,4 \\
\hline
\end{tabular}

*FUENTE: EPA. 1er trimestre de cada año.

** FUENTE: Eurostat

Pero lo que verdaderamente importa no es el mero dato estadístico, sino dónde y cómo se insertan estos jóvenes, qué tipos de contratos reciben, qué posibilidad tienen de planificar su vida.

Cuando sólo se hace referencia a los datos estadísticos, se presentan, por una parte, las desigualdades como una distribución estadística de las mismas, en las que no aparecen las características reales y sociales de las personas que se suman en esa estadística, y por otra, es tanto el valor mediático que se da a las estadísticas del paro, que parece como si las estadísticas tuvieran la culpa del paro: la discusión y utilización, según intereses concretos, de las cifras del paro, si provienen del paro registrado -datos del INEM- o provienen de la Encuesta de Población Activa -EPA- y el interés por reducir, a toda costa, los datos estadísticos del paro.

Parece como si no importara el tipo de contrato, ni su duración, ni la interrupción, ni que sea sólo para los fines de semana, para no pagar seguridad social, ni las condiciones del trabajo, ni saber cuándo y cómo obtendrán un trabajo estable, ni saber qué posibilidades tienen de interpretar y organizar el significado de las situaciones a las que tienen que enfrentarse cada día... lo que importa es que contabilice estadísticamente y que "disminuya" la cifra de paro.

Un análisis científico de los datos estadísticos y de su evolución también tiene en cuenta las características de las personas a las que hace referencia y puede ser un soporte valioso para elaborar medidas socio-educativas.

Mayoritariamente los jóvenes obtienen ocupaciones como trabajadores no cualificados y de servicios.

La tabla siguiente muestra cómo los grupos de ocupaciones donde más trabajan los jóvenes son los de trabajadores no cualificados y tra- 
bajadores de servicios de restauración, personales, protección y vendedores de comercio. Suponen casi la mitad de todos los jóvenes trabajadores menores de 25 años (un 45,76\%). Y menos de un $10 \%$ ocupan puestos de técnicos.

Estos puestos en trabajos escasamente cualificados no se corresponden con el nivel de formación que estos jóvenes tienen; ya que el $80 \%$ del total de jóvenes de entre 16 y 24 años tienen estudios secun-

Tabla 4. Población ocupada por edad y grupos de ocupación en el año 99.

Total Nacional. (En miles y \% respecto del total).

\begin{tabular}{|l|r|r|}
\hline Grandes Grupos de ocupación & $\mathbf{1 6 - 2 4}$ años & \multicolumn{1}{c|}{$\%$} \\
\hline Directivos de empresas y de la Administración pública & 25.9 & 1.47 \\
\hline Técnicos y profesionales científicos e intelectuales & 68.2 & 3.88 \\
\hline Técnicos y profesionales de apoyo & 94.2 & 5.36 \\
\hline Empleados de tipo administrativo & 157.7 & 8.97 \\
\hline $\begin{array}{l}\text { Trabajadores de servicios de restauración, personales, } \\
\text { protección y vendedores de comercio }\end{array}$ & 402.0 & 22.88 \\
\hline Trabajadores cualificados en agricultura y pesca & 48.9 & 2.78 \\
\hline $\begin{array}{l}\text { Artesanos y trabaj. cualificados de industrias } \\
\text { manufactureras, construcción y minería }\end{array}$ & 351.3 & 19.99 \\
\hline Operadores de instalaciones y maquinaria. Montadores & 190.0 & 10.81 \\
\hline Trabajadores no cualificados & 402.0 & 22.88 \\
\hline Fuerzas armadas & 17.1 & 0.97 \\
\hline TOTAL & 1.757 .3 & \\
\hline
\end{tabular}

FUENTE: EPA 99, II Trimestre.

Tabla 5. Población por estudios terminados y edad. Año 99.

Total Nacional. (En miles y \% respecto del total).

\begin{tabular}{|l|r|r|}
\hline Estudios terminados & $\mathbf{1 6 - 2 4}$ años & $\%$ \\
\hline Analfabetos & 16.9 & 0.72 \\
\hline Sin estudios & 42.7 & 1.82 \\
\hline Primarios & 278.3 & 11.87 \\
\hline Secundarios o medios & 1.631 .1 & 69.54 \\
\hline Técnico-profesionales superiores & 243.6 & 10.39 \\
\hline 1er Ciclo & 75.5 & 3.22 \\
\hline $2^{\circ}$ Ciclo & 56.0 & 2.39 \\
\hline Otros estudios postsecundarios & 1.3 & 0.06 \\
\hline TOTAL & 2.345 .4 & \\
\hline
\end{tabular}

FUENTE: EPA, 99. II Trimestre. 
darios o medios y técnico-profesionales superiores, de lo que se puede deducir que tienen una suficiente preparación a nivel formativo, como para ocupar puestos en trabajos cualificados, en vez de los mayoritarios puestos no cualificados en que los jóvenes trabajan.

Por otro lado, respecto al cómo y en qué condiciones se insertan los jóvenes hay que tener en cuenta el tipo de contrato con el que trabajan.

\subsubsection{Juventud y tipos de contratación}

El primer dato observable es el mayor volumen de contrataciones que firman las cohortes jóvenes con respecto al resto de cohortes de edad. Los jóvenes de edades comprendidas entre 20-24 años son los que mayor número de contratos firman, y suponen el $25-26 \%$ del total de contrataciones firmadas anualmente. Los jóvenes en edad de "asentamiento laboral", entre 25 y 29 años, firman el $21 \%$ del total de contratos celebrados.

Si a los datos anteriores, añadimos que entre un $8-9 \%$ de los contratos son firmados por jóvenes en periodo de "iniciación laboral", 16-19 años, podemos significar que el $50 \%$ de las contrataciones celebradas, son realizadas por jóvenes.

Tabla 6. Contratos firmados distribuidos porcentualmente según cohortes de edad, durante el periodo 1996-1999 (\% horizontales).

\begin{tabular}{|c|c|c|c|c|c|c|c|c|c|c|c|}
\hline & \multirow{2}{*}{$\begin{array}{l}\text { Contratos } \\
\text { Firmados }\end{array}$} & \multicolumn{10}{|c|}{ SEGUN LA EDAD (en \% horizontal) } \\
\hline & & $16-19$ & 20-24 & 25-29 & $30-34$ & 35-39 & $40-44$ & $45-49$ & $50-54$ & $55-59$ & $>59$ \\
\hline 1996 & 8.601 .119 & 8,3 & 25,1 & 21,6 & 14,8 & 10,5 & 7,3 & 5,5 & 3,8 & 2,1 & 1,0 \\
\hline 1997 & 9.807 .514 & 8,6 & 25,6 & 21,6 & 14,6 & 10,4 & 7,3 & 5,4 & 3,7 & 1,9 & 0,9 \\
\hline 1998 & 11.663 .279 & 9,0 & 25,9 & 21,5 & 14,4 & 10,3 & 7,3 & 5,3 & 3,7 & 1,9 & 0,9 \\
\hline 1999 & 10.986 .722 & 9,5 & 26,0 & 21,2 & 14,1 & 10,3 & 7,4 & 5,1 & 3,6 & 1,9 & 0,8 \\
\hline
\end{tabular}

FUENTE: Contratos registrados. INEM.

Pese a que el número de contrataciones ha variado enormemente en los últimos años, la distribución porcentual del número de contrataciones registradas, según la edad de los firmantes, no ha variado substancialmente, si bien se observa un ligero aumento en el porcentaje de contrataciones firmadas por los más jóvenes, 16-19 y 20-24 años.

El resto de cohortes de edad han visto como su porcentaje de contrataciones, respecto del total de contrataciones firmadas, disminuía pese a crecer numéricamente, puesto que el número de contrataciones, como ya se ha indicado, ha crecido significativamente durante los últimos años. 
La frase que mejor resumiría los datos presentados hasta ahora es que los jóvenes son los que más contratos firman, tanto numérica como porcentualmente.

Otra de las cuestiones que a menudo se suelen citar como dato relevante, que también se puede comprobar claramente, es el que los jóvenes entre 16 y 19 años firmaron en 1998 una media de 3,2 contratos por persona, mientras que los adultos de la cohorte 40-44 años celebraron 0,5 contratos por persona/año y los adultos de la cohorte de 59 y más años firmaron $0,2 \%$ contratos por persona/año. El análisis de los tres años 1996-1998 nos ofrece una visión significativa de la situación laboral de los colectivos según su edad. La rotación laboral decrece conforme aumenta la cohorte de edad. Esta constatación muestra la precariedad de la situación laboral de los jóvenes, reflejada en el tipo de contrato. Algunos estudios sobre juventud y empleo señalan que, conforme aumenta la edad de las personas, la precariedad laboral disminuye, mejorando los tipos de contratos firmados.

\subsubsection{Jóvenes y mercado de trabajo: Análisis de las tasas de ac- tividad}

Las tasas de actividad al igual que las tasas de desempleo y ocupación son muy sensibles a las variables de sexo y edad; el paro afecta con más fuerza a las mujeres, pero sobre todo a los jóvenes.

Con el objeto de situar al lector ante el panorama laboral en el que nos encontramos actualmente, es necesario introducirle previa y brevemente en las características que componen nuestra población activa.

A partir de la década de los 80 la población activa se ha hecho cada vez más numerosa, menos juvenil y más femenina. Fenómeno bastante generalizado en el Estado español.

La tasa de actividad en el Estado español se situaba a finales de 1999 en un $50,69 \%$ de la población, habiendo registrado un crecimiento de 1,8 puntos.

En lo que a la progresiva feminización de la población activa se refiere, hay que señalar varios datos que confirman este punto:

- En 1980, la tasa de actividad femenina a nivel nacional se situaba en el $27,17 \%$, mientras que en 1990 lo hacía ya en el 33,51\%, para situarse en la actualidad en el $39,11 \%$.

Por el contrario la tasa de actividad masculina ha decrecido durante este periodo de tiempo. Tal es así que en 1980 la tasa de actividad masculina era del $71,70 \%$, en 1990 del $66,48 \%$, y en la actualidad representa el $63,27 \%$. 
- En lo que al periodo 94-99 se refiere, se puede observar el mismo proceso, en donde mientras que los hombres han visto como su tasa de actividad se incrementaba levemente (un punto) respecto de 1994, la tasa de actividad femenina ha crecido en 3,3 puntos .

Tabla 7. Comparación de las tasas de actividad según género a nivel nacional durante el sexenio (1994-1999).

\begin{tabular}{|l|c|c|c|}
\hline España & Ambos sexos & Varones & Mujeres \\
\hline 1994 & 48,82 & 62,74 & 35,8 \\
\hline 1995 & 49,14 & 62,77 & 36,48 \\
\hline 1996 & 49,78 & 63,2 & 37,24 \\
\hline 1997 & 49,99 & 63,06 & 37,79 \\
\hline 1998 & 50,02 & 63,17 & 37,91 \\
\hline 1999 & 50,69 & 63,27 & 39,11 \\
\hline
\end{tabular}

En cuanto a las tasas de actividad atendiendo a los diferentes grupos de edad, hay varios aspectos sobre los que incidir.

En primer lugar, y casi de forma obvia, es obligado constatar que las tasas de actividad de los más jóvenes (16-19 años) son unas tasas considerablemente inferiores a las obtenidas por los jóvenes entre $20 \mathrm{y}$ 24 años. Ello se debe principalmente a que el periodo de escolarización de este grupo de edad es muy elevado. La influencia de la prolongación del período de estudios se hace notar en las tasas de actividad de tal forma que, como ejemplo, sirva que a nivel nacional la tasa de actividad de este grupo de edad se situaba en 1980 en el $46 \%$ mientras que en la actualidad se sitúa en el $25 \%$.

El grupo de edad 20-24 años es considerado como el grupo de edad en el que da comienzo la iniciación laboral, tras la finalización de los estudios, y lógicamente ello se hace notar en las estadísticas. La tasa de actividad de este grupo se ha mantenido estable en la media nacional, en torno al $60 \%$.

Respecto de las tasas de actividad del grupo de edad 25-54 años se da un proceso de crecimiento de la tasa de actividad a nivel nacional. En la evolución de esta tasa tiene mucho que ver la incorporación femenina al mercado laboral que ya se ha señalado con anterioridad. Como dato puede servir que la tasa de actividad femenina en 1980 para este grupo de edad se situaba en el $30,7 \%$ mientras que en la actualidad se sitúa en el $61,3 \%$. 
Tabla 8 . Comparación de las tasas de actividad según grupos de edad, a nivel nacional durante el sexenio (1994-1999).

\begin{tabular}{|l|c|c|c|c|}
\hline España & $\mathbf{1 6 - 1 9}$ & $\mathbf{2 0 - 2 4}$ & $\mathbf{2 5 - 5 4}$ & $\mathbf{5 5}$ y más \\
\hline 1994 & 25,86 & 62,31 & 73,69 & 15,84 \\
\hline 1995 & 23,85 & 60,86 & 74,08 & 16,18 \\
\hline 1996 & 24,55 & 59,55 & 74,88 & 16,00 \\
\hline 1997 & 23,65 & 59,55 & 75,40 & 16,00 \\
\hline 1998 & 24,46 & 59,53 & 75,87 & 15,50 \\
\hline 1999 & 25,41 & 60,37 & 76,71 & 15,61 \\
\hline
\end{tabular}

2.2.3. El desempleo. Análisis y evolución de las tasas de desempleo

Durante el período de implantación del Programa Operativo Objetivo $\mathrm{n}^{\circ} 3$ en varias regiones de España (1994-1999), la evolución de la reducción de las tasas de desempleo, tanto a nivel nacional como a nivel de esas regiones, ha sido muy positiva. De hecho la tasa de desempleo a nivel nacional se situaba en 1994 en el 23,91\%, mientras que en el último trimestre de 1999 había descendido hasta situarse en un $15,43 \%$. Ello significa un descenso significativo de más de 8 puntos.

Tabla 9. Comparación de las tasas de paro según género, durante el sexenio (1994-1999).

\begin{tabular}{|l|c|c|c|}
\hline España & Total & Varones & Mujeres \\
\hline 1994 & 23,91 & 19,16 & 31,69 \\
\hline 1995 & 22,77 & 18,10 & 30,22 \\
\hline 1996 & 21,77 & 17,15 & 29,11 \\
\hline 1997 & 20,32 & 15,39 & 27,99 \\
\hline 1998 & 18,17 & 13,06 & 26,03 \\
\hline 1999 & 15,43 & 10,75 & 22,40 \\
\hline
\end{tabular}

Como bien es sabido, las tasas de desempleo presentan sensibles diferencias si analizamos colectivos determinados, como jóvenes y mujeres.

$\mathrm{Si}$ atendemos a las tasas generales de desempleo según el género podemos observar lo siguiente:

- En primer lugar, constatar lo evidente: las tasas de desempleo femenino son mucho más elevadas que las del desempleo masculino, sea cual sea el año que observemos. Manifestándose la desigual- 
dad de acceso al mercado laboral según género.

- En segundo lugar la evolución de las tasas de desempleo femenino han discurrido generalmente paralelas a la disminución de las tasas de desempleo masculino. De estos datos se desprende que la incorporación laboral ha sido muy similar en ambos géneros. La bonanza del ciclo económico y la creación de empleos parece pues haber afectado por igual a ambos géneros

Ambos puntos de análisis reflejan que el mercado laboral, pese a mantener todavía diferencias significativas en la accesibilidad al mismo según el género de las personas, se encuentran "indicios" que permiten observar que con la mejora del ciclo económico y la creación de nuevas posibilidades de empleo, las diferencias según género tienden a equipararse.

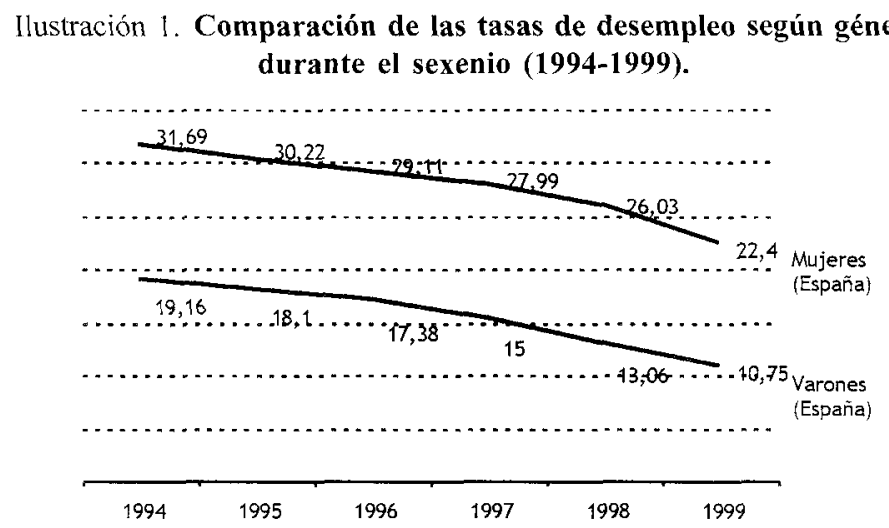

FUENTE: INE-EPA. Web del Instituto Nacional de Estadística.

De la observación de las tasas de desempleo obtenidas durante el sexenio 1994-1999, se desprenden varios comentarios de interés:

- En primer lugar, y al igual que con el grupo de las mujeres, se confirma la mayor dificultad para acceder al mercado laboral por parte de los grupos de edad jóvenes (16-19 y 20-24 años). Puesto que en ambos grupos, las tasas de desempleo superan ampliamente la media nacional.

- Es necesario constatar la mejora prolongada que las tasas de desempleo juvenil han tenido durante el periodo observado (1994-1999). De hecho y por poner un ejemplo, a nivel nacional, los jóvenes entre 16 y 19 años poseían en 1994 una tasa de desempleo del 53,1\%, mientras que a finales de 1999 la tasa es del 37,73\%, dándose por tanto una reducción de cerca de 15 puntos. Similar es el dato para 
el grupo de edad de 20/24 años, donde la reducción de la tasa de desempleo es igualmente de 15 puntos.

Por el contrario, en los grupos de edad superiores, los porcentajes de reducción de las tasa de desempleo han sido mucho menores. Conforme aumenta el grupo de edad, disminuye la posibilidad de variación de la tasa de desempleo. Ello apunta hacia el hecho de que el colectivo joven pese a ser el que mayores dificultades de inserción posee, en los momentos de tirón económico es el que más beneficiado sale del mismo, viendo disminuir su tasa de desempleo progresivamente.

Tabla 10. Comparación de las tasas de paro según grupo de edad, durante el sexenio (1994-1999)

\begin{tabular}{|l|c|c|c|c|}
\hline España & $\mathbf{1 6 - 1 9}$ & $\mathbf{2 0 - 2 4}$ & $\mathbf{2 5 - 5 4}$ & $\mathbf{5 5}$ y más \\
\hline 1994 & 53,10 & 41,59 & 20,69 & 11,93 \\
\hline 1995 & 50,09 & 39,96 & 19,88 & 11,16 \\
\hline 1996 & 52,12 & 37,95 & 18,83 & 10,89 \\
\hline 1997 & 49,89 & 34,67 & 17,79 & 10,55 \\
\hline 1998 & 43,65 & 31,42 & 15,91 & 10,06 \\
\hline 1999 & 37,73 & 25,98 & 13,54 & 9,64 \\
\hline
\end{tabular}

Se puede observar que a nivel nacional, la evolución de la tasa de paro total tiene un efecto mayor sobre la tasa de paro de los jóvenes que sobre la del resto de grupos de edad. Ello significa que el ciclo económico afecta en mayor medida a los jóvenes que a los adultos, de

Ilustración 2. Evolución de las tasas de paro según grupo de edad, a nivel nacional durante el sexenio (1994-1999).
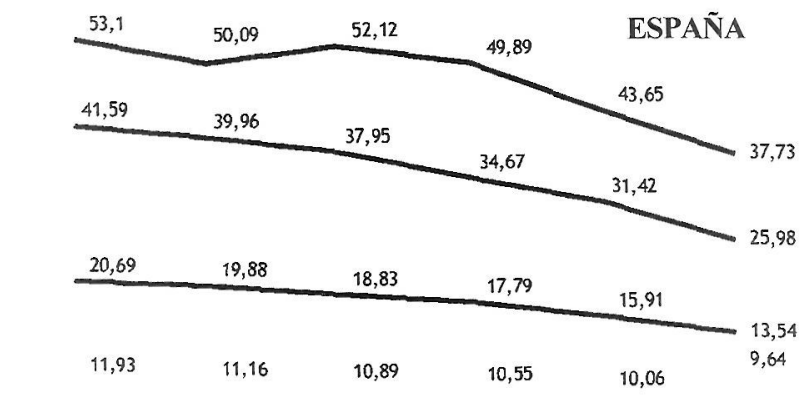

$\begin{array}{lcccc}1994 & 1996 & 1997 & 1998 & 1999 \\ & 16-19 \text { años } & & \\ 20-24 \text { años } & & 25-54 \text { años } \\ & & 55 \text { y más años }\end{array}$


forma que pareciese que en épocas expansivas de la economía la disminución de la tasa de paro juvenil parece ser de mayor magnitud que la disminución de la tasa de paro agregada (total), mientas que en los periodos de menor crecimiento económico, los jóvenes se enfrentaran a peores condiciones a la hora de encontrar un empleo.

El problema de no tener trabajo es algo más que una cifra estadística. Abarca a muchos tipos de jóvenes, por un lado los jóvenes que se encuentran fuera del marco estructurador del sistema escolar y con problemáticas personales y sociales, son jóvenes que se pueden encontrar en situación de exclusión social .Y por otro lado, otros jóvenes titulados universitarios o con titulación media que cuentan con más recursos formativos y personales y que pueden competir con los otros jóvenes y desplazarles de sus posibles puestos de trabajo.

\section{LA INDEPENDENCIA, ¿OBJETIVO O ILUSIÓN?}

Podemos concluir afirmando que alcanzar la independencia económica es cada día un proceso más largo y difícil, y los/las jóvenes dedican todo su tiempo a lograrlo. Se alarga en el tiempo la adquisición de una situación estable en el ámbito del trabajo, siendo pues los más jóvenes y las mujeres los sectores de la población más vulnerable en épocas de vacas flacas, al mismo tiempo que son los que mayor inestabilidad arrojan incluso alcanzando el objetivo del empleo por los constantes cambios de puesto de trabajo, de tipo de trabajo, de empresa en la que trabajan, etc. Y aunque no han dejado de tener grandes dosis de generosidad e idealismo, como se demuestra en su participación en el voluntariado y en los movimientos sociales, saben también estos jóvenes que la independencia económica se la deben ganar ellos mismos.

Ya no existen modelos de itinerarios educativos y sociales garantizados que les prometan alcanzar la meta deseada: han desaparecido los modelos tradicionales de vida, han desaparecido para un parte importante de ellos los itinerarios lineales, y están abocados los jóvenes a tener que hallar ellos mismos su propio camino.

¿Solos? Esta es la cuestión que se plantea, ¿quiénes acompañan o deben acompañar a los jóvenes en una sociedad sin modelos de vida, sin estilos de vida valederos para todos ni siquiera para la mayoría?. Desde el inicio de los orígenes del trabajo social americano y europeo en la revolución industrial del siglo XIX fue la preocupación por los jóvenes una constante. Baste recordar que las llamadas casas de rehabilitación o asentamientos eran centros cívicos "en los que se dio un gran impulso reformador al trabajo pedagógico-social institucional, so- 
bre todo en lo que se refiere al cuidado de madres y niños, la educación extraescolar y extrafamiliar a los jóvenes y a los niños a través de clubs, a los centros de enseñanza escolar, a la atención a los minusválidos, a los centros de tiempo libre para los escolares, a la administración local de ayuda a los pobres y a las propias sociedades caritativas" (Buck 1982, p. 124). Los/las trabajadores sociales españoles van recuperando ese espacio de apoyo a los jóvenes que perdieron durante la transición española, más atentos en ese momento a las reivindicaciones de estudios universitarios para su profesión, a la consolidación del estado de bienestar en España y a la creación de servicios sociales, tareas por otro lado de gran alcance e importancia para garantizar derechos sociales, proteger a los grupos más débiles de la sociedad.

Actualmente se encuentran trabajadores/as sociales realizando proyectos de atención, apoyo y acompañamiento a los jóvenes, así como en proyectos innovadores de inserción laboral, participan en asociaciones de tiempo libre, en la programación y en la gestión de actividades de ocio y tiempo libre para jóvenes, así como en instituciones y entidades formativas, incluso en el sistema escolar participando en los departamentos de orientación. Recuperando pues un espacio tan sumamente propio del trabajo social dedicado a la mayor y mejor integración social y por tanto laboral de una parte de la población que se distingue por su vulnerabilidad, o en la que se reflejan de un modo in-disimulado las contradicciones que comporta nuestra sociedad, que al mismo tiempo que exige ser uno/a mismo/a, no crea las condiciones sociales y económicas necesarias para cumplir con esa exigencia.

\section{APROXIMACIÓN TEÓRICA A LAS TRANSICIONES Y CAMBIO SOCIAL}

Para explicar el problema no es suficiente constatar la prolongación de las transiciones, el efecto yoyo, o el aumento de la dependencia, sino que además hay que reflexionar sobre los nuevos modelos teóricos que explican la diversidad y la reversibilidad en las condiciones de la vida joven. Beck y Giddens han teorizado sobre el impacto de la modernización en los jóvenes.

En particular la obra de Beck y su tesis sobre la individualización han tenido una influencia particular. Siguiendo a Beck, constatamos que la gente se ha ido liberando progresivamente de las restricciones y obligaciones del orden viejo y de la tradición y se ha tenido que ir enfrentando a una batería de nuevas oportunidades y de nuevos riesgos. Si la sociedad industrial se caracterizaba porque era previsible, en la 
segunda modernidad uno/a se ve abocado/a a hacer su planes y a construir su propia biografía.

Los individuos más que nunca se ven abocados a sí mismos. Las instituciones sociales surgidas como ayuda al individuo han perdido su plausibilidad. Sus normas y valores quedan en entredicho, la sociedad del átomo y de la química poseen un potencial explosivo. Las instituciones, en su competencia por asegurar la vida de las personas, se quedan en evidencia al constatar que no lo pueden hacer. Si la era industrial se apoyó en un consenso de progreso, que ha legitimado en principio el desarrollo técnico y económico durante la primera fase de la era industrial, "ahí donde se ha infringido de manera global, palmaria y sistemática este contrato de seguridad, el consenso respecto del progreso deja de ser, él mismo en consecuencia algo indiscutible" (Beck, 1994, p. 23), el progreso como tal queda cuestionado.

Si esto es así, no es raro que hablemos de una sociedad en "permanente crisis", algunos hablan de una sociedad en la que la revolución se está llevando a cabo en silencio, cuasi de un modo imperceptible.

La consecuencia es doble. Por un lado el individuo queda relegado a sí mismo. El resultado es un tipo de ciudadano/a que debe valerse por sí mismo/a. Las formas sociales, ritos, costumbres, moral compartida, control social y solidaridad pierden interés y relevancia en una sociedad de individuos ocupados en, como dice Hamburger, "coordinar sus roles, integrar su personalidad y formar su identidad" (1996, p. 50). El éxito de esa preocupación depende naturalmente una vez más de las oportunidades que le ofrece la propia sociedad.

Este proceso de acentuación del individuo se ha denominado como proceso de individualización. La individualización implica que las personas de esta sociedad pueden liberarse de muchas presiones sociales, de muchos condicionamientos del medio social y pueden desarrollar en libertad sus propios estilos de vida, sin preguntar al vecino lo que le parece, ni a sus mayores, ni al colectivo en el que se incluye. Libertad, singularidad y aumento de formas de vida es la oportunidad que nos ofrece la sociedad de la segunda modernidad.

Pero al mismo tiempo, de ahí una vez más su ambivalencia, el individuo ya no puede recurrir al exterior, sociedad, familia o medio social para recabar ayudas, orientación de vida y ejemplos para su situación individual. Las normas sociales, los estilos de vida comunes, los vínculos religiosos y/o morales pierden su plausibilidad, su legitimidad y su influencia. El pacto de progreso que caracterizó en décadas anteriores a la sociedad industrial ha dejado de funcionar. El individuo tiene que inventarse su propia vida, escribir su propia biografía. 
El aumento de libertad y de opciones conlleva también la pérdida de vinculación, de sentido, y de anclaje.

El/la joven, en esta sociedad, sobre el trasfondo de un nivel de vida material relativamente llevadero y un número grande de seguridades y garantías sociales, se encuentra a la vez en unas condiciones sociales de diversas rupturas. Ruptura con las condiciones de vida comunes, con las regularidades que proporciona la tradición, la familia, el clan el grupo de referencia, encontrándose la persona sola ante el destino que se ha convertido en individual, con todos los riesgos, condiciones y contradicciones existentes en esta sociedad. El/la joven, como miembro de esta sociedad, una sociedad globalizada y fragmentada al mismo tiempo y sin un eje entorno al que orientar su vida se siente más que nunca relegado a sí mismo, con todos los riesgos que ello conlleva.

Los jóvenes tienen las puertas abiertas a la educación/formación, pero cerradas al mercado laboral o al menos su acceso es en precario, es reversible. Aquí hay una gran brecha, una gran ruptura entre la formación, mayoritariamente realizada en la escuela, y los ámbitos laborales. La formación necesaria por un lado no es garantía de empleo por otro.

Los problemas de transición son cada vez más complicados. Es típico que los jóvenes puedan participar en casi todos los ámbitos de la educación, como ya hemos señalado, y sin embargo tienen serios problemas para integrarse en el mundo laboral de modo estable.

La planificación del futuro de la propia vida, el acceso a una vivienda, la proyección de unas relaciones estables de pareja, y otras tantas cosas más se resienten de tal manera que puede estar condicionando una posición de desilusión, de frustración en los jóvenes, que a algunos les lleve a "pasar" de esta sociedad, a otros a procesos de agresividad destructora contra la propia sociedad, y contra sí mismos, a través del consumo de drogas, alcohol, etc. a otros a refugiarse en lo que se ha llamado subculturas juveniles, o más recientemente denominadas tribus urbanas.

El fenómeno de la permanencia de los jóvenes en la mansión paterno-materna que se detecta en España con un $77 \%$ de permanencia hasta casi los 30 años (Martín Serrano /Velarde, 2001, p.65)) tiene que ver también con el fenómeno de la precarización, dando lugar a lo que se ha denominado como polarización socioeconómica que lleva consigo la ruptura y disociación con la seguridades que emanan del trabajo seguro y del salario (Alisch/Dangschat 1998).

Los/las jóvenes relegados a sí mismos, sin los mecanismos clásicos de transición lineal de escuela, -formación profesional/estudio/traba- 
jo-, sin "la trilogía típica del transcurso de la vida" como le llama Timmermann (1998) "preparación para la vida" (profesional), "actividad profesional" y "jubilación" (de la profesión) (p. 19), puede que no encuentren tan atractiva esta sociedad de la multiopcionalidad, y se conviertan en fácil clientela de sectas, ideólogos de todo tipo o simplemente, como venimos observando en investigaciones nacionales e internacionales, se refugien en valores de carácter privatísimo, la familia, las relaciones personales, los grupos de referencia, de iguales o coetáneos, al consumo (Martín Serrano, 1994; Juventud Valenciana, 1995) incluso, como ya apuntaron algunos sociólogos al final de la década de los 80 , que empiecen a relativizar, si no ya a rechazar incluso, el valor del trabajo, en una sociedad que se lo niega. Sin seguridades, sin un futuro seguro, los/las jóvenes difícilmente podrán hacer suya la democracia, dando así opción a nuevos y viejos regímenes totalitarios.

Sin embargo, la sociedad mantiene el trabajo asalariado como eje en torno al que se configura la integración social.

Efectivamente tener trabajo tiene un valor simbólico muy importante. Tener trabajo significa:

- poderse independizar de los progenitores,

- poder acceder a bienes de consumo y de cultura,

- ser alguien en la sociedad, revalorizando la propia persona, la autoestima,

- tomar decisiones con libertad: comprar o alquilar una vivienda, casarse, procrear,

- identificarse (por lo menos en buena parte) con la propia sociedad,

- desarrollar una ética de la responsabilidad y del deber.

En definitiva y como dice A. Serrano Pascual (1995), la inserción al trabajo actúa como una importante fuente de reconocimiento, así como de reproducción social (p. 180, Reis, núm 71-72). La función socializadora del trabajo remunerado se mantiene a pesar de que para muchos esa instancia socializadora ha dejado de funcionar, sometidos a los procesos de precarización del empleo, si no ya a su exclusión.

El efecto contrario es de prever que pueda darse por parte de los jóvenes un rechazo a la sociedad, ante las condiciones de precariedad, un rechazo que afecta no sólo al trabajo, sino también a la sociedad en su conjunto y a los propios adultos. No es pues de extrañar que se hable ya de "biografías interrumpidas", "procesos de socialización incompletos", falta de identidad, etc. entre los jóvenes, y que de agudizarse pueda dar al traste con lo que hemos denominado, (véase López-Blasco 1996) como "armonía aparente" (p.198). 


\section{LA FUNCIÓN CAMBIANTE DE LA FAMILIA EN LAS TRANSICIONES DE LOS/LAS JÓVENES}

Las funciones que la familia viene realizando a través de las diversas épocas han ido cambiando según circunstancias y situaciones, épocas y condicionamientos. Muchas de las funciones anteriores referidas a la educación de la prole, a la atención sanitaria, y a la atención a los mayores han pasado a manos de instituciones públicas y/o privadas, han sido asumidas por el Estado del Bienestar o han pasado a segundo plano. Esto no quiere decir que las familias no sigan jugando algún papel importante incluso en estos ámbitos y necesidades de las personas, sino que ya no son ni exclusivas, ni exigibles, ni propias de ellas. Existe toda una serie de instituciones que han asumido algunas de las funciones que la familia venía cumpliendo tradicionalmente. De modo que tengamos que replantearnos la cuestión de las funciones de las familias actualmente.

Sin querer despegar aquí una discusión al respecto, ni en la profundidad que requiere el tema, nos referiremos sobre todo a las funciones que curiosamente, si no ya paradójicamente, se han relegado al ámbito familiar en los últimos años. Lo hemos mencionado ya anteriormente y volvemos ahora sobre ello para explicitarlo en el contexto de la situación de los jóvenes y su proyección de futuro.

La familia cumple con la función de colchón social, de válvula de escape para que la situación social no se incline por la explosión o revuelta social, se mantenga una cierta tensión sin que sea peligrosa para el propia sistema y por otro con la función de servir de refugio y lugar protegido para los jóvenes, mayores de 18 años, desde donde pueden esperar, con menos riesgos, a tiempos mejores. Esto es, a que puedan alcanzar la mayoría de edad, no en el sentido jurídico ni cronológico, sino en el sentido emocional, la estabilidad social y laboral que les permita vivir independientemente de sus progenitores, y ello durante un largo tiempo que alcanza en un porcentaje muy alto $(77 \%)$ hasta los 30 años y en algunos casos, si bien los menos, a más edad.

La larga permanencia de los/las jóvenes en la familia de origen es la consecuencia de esta situación de inseguridad y de precariedad que le hace buscar y conseguir en la familia un seguro ante las nuevas dificultades y los nuevos retos.

La familia sustituye a la sociedad en su conjunto y a sus instituciones. Nosotros creemos que al igual que en otros ámbitos, como el educativo, el social y el sanitario la sociedad ha asumido funciones que en épocas anteriores cumplía la familia, ahora parecería obvio que debería asumir también en el caso de los jóvenes en sus transiciones. Cosa 
que claramente no hace.

Más aún la familia es la instancia más utilizada para buscar empleo, sostiene económica y socialmente a los jóvenes mientras no tienen ingresos propios, incluso cuando los tienen (durante los primeros años), y les ofrece la posibilidad de permanecer en la vivienda con sus progenitores hasta que deciden o puedan emanciparse. Esta situación lleva consigo que se retrase la edad de la creación de núcleos familiares independientes y que descienda la natalidad.

Es decir, que la propia sociedad al inhibirse ante un problema de un sector importante de la sociedad, la estabilización emocional, social y económica de los jóvenes en sus transiciones, pagan el alto precio de la pérdida de núcleos familiares y de la renovación generacional.

Tabla 11. Porcentaje de jóvenes 26-29 años que viven con sus padres.

\begin{tabular}{|l|l|l|l|}
\hline $\mathbf{1 9 9 0}$ & $\mathbf{1 9 9 6}$ & $\mathbf{1 9 9 8}$ & $\mathbf{2 0 0 0}$ \\
\hline $25 \%$ & $46 \%$ & $53 \%$ & $50 \%$ \\
\hline
\end{tabular}

FUENTES: Martín Serrano, M. y Velarde, O. Informe de Juventud de España 96. Martín Serrano, M. y Velarde, O. Encuesta a jóvenes de 21 a 29 años, 1998. Informe sobre España, Proyecto TSER (AREA) Junio 2000. Martín Serrano/Velarde: Informe de Juventud 2000.

Según De Miguel, A. (2000), "el 55\% de los jóvenes de 16 a 20 años no se ha planteado independizarse de los padres y el $29 \%$ a veces piensa en ello, pero no le preocupa demasiado. En conjunto el $84 \%$ de los jóvenes adolescentes no contempla esa posibilidad. Con esa misma edad, el $11 \%$ responde que cada día le preocupa más seguir viviendo con sus padres aunque ve lejana su emancipación. Tan sólo el $8 \%$ cree que le queda poco para empezar a vivir por su cuenta. A medida que aumenta la edad más cerca ven los jóvenes que viven con sus padres la posibilidad de independizarse. A la edad de 21-24 años, el 17\% de los jóvenes que viven con sus padres creen que les queda poco para emanciparse. La proporción se eleva al $28 \%$ de los jóvenes de 25 a 29 años. Pero, tampoco es que sea muy elevada. Responden que les preocupa, aunque vean lejana esa posibilidad el $21 \%$ de los jóvenes de 21 a 24 años y el $28 \%$ de los jóvenes de 25 a 29 años.

Por último, para el $62 \%$ de 21 a 24 años y para el $45 \%$ de 25 a 29 años no es algo que les inquiete demasiado. Es más, un tercio de los jóvenes de 21 a 24 años y dos de cada diez de 25 a 29 años no se plantean su emancipación. Diríase que muchos jóvenes han conseguido detener el tiempo" (p.218). 
Desde hace unos años venimos observando que aumenta la permanencia de los jóvenes en las familias de origen. También se observa que aumenta en los otros países de la Unión Europea. La tendencia mayoritaria a abandonar la familia muy pronto entre los años sesenta y los ochenta se ha parado e incluso es reversible en muchos países (Eurostat 1997).

Los porcentajes en la UE se mueven, para los jóvenes entre 20-24, entre el $29 \%$ (el más bajo) que todavía vive en casa de sus padres en Finlandia y el 89\% en España; los jóvenes entre 25-29 años viven con sus familias de origen, el 9\% en Finlandia y el 50\% en España.

Además de las transiciones al mundo laboral, el joven está inmerso en una serie de transiciones que tienen lugar en diferentes áreas de la vida: relación de pareja y sexualidad, desarrollo de estilos individuales de vida y de independencia de su familia.

Tradicionalmente estas transiciones se solían entender como un cambio de estatus del joven al adulto. Pero, al no darse una transición lineal, la realidad es mucho más compleja y las decisiones entre las diferentes áreas se entrecruzan, teniendo por ejemplo una transición en la relaciones de pareja y sexualidad, sin conseguir la transición al desarrollo de un estilo de vida independiente de la familia. La lógica y los ritmos de las transiciones se han diversificado tanto que los jóvenes tienen que tomar, a veces, decisiones biográficas contradictorias.

Por ello creemos que no se puede reducir la explicación de la permanencia en la familia de origen y las transiciones a una dimensión económica.

Explicarlo sólo porque necesitan una ayuda económica significa reducir la situación de los jóvenes a un problema económico, dejando fuera su realidad social.

En estudios recientes aparece como algo importante el soporte familiar, el soporte emocional para contrarrestar la ansiedad (Deutsche Shell, 2000), o más acertadamente la inseguridad cada día mayor, que produce la difícil transición al mundo laboral y a las otras manifestaciones de la edad adulta, creación de núcleo familiar, en una sociedad que ella misma se encuentra en un proceso de las más agudas transformaciones que ha sufrido después de la revolución industrial. Nos referimos a la sociedad de la información como la ha llamado el sociólogo español más destacado a nivel internacional el aragonés-catalán Manuel Castells 1997. Beck (1999) por su parte nos recuerda que una sociedad en la que se desregula y flexibiliza el trabajo está en proceso de convertirse de una sociedad del trabajo a una sociedad del riesgo. Ni la política ni la economía serán capaces de descifrar las consecuen- 
cias que ello va a tener no sólo para la economía sino también para la propia sociedad y concluye "una cosa está clara: una inseguridad endémica será la señal que caracterice en el futuro el mundo de la vida (Lebenswelt) y los fundamentos de la vida -también para aquellos de las clases medias (el centro) a quienes aparentemente parece irles bien-" (pag. 10).

\section{FAMILIA Y RELACIONES INTERGENERACIONALES}

En el año 1999, la casi totalidad de los jóvenes españoles de 15 a 24 años están solteros $(94,5 \%)$. Entre los pocos que han iniciado una vida conyugal estable, predominan los casados frente a los que viven en "unión libre", aunque en los últimos 4 años se aprecia un ligero incremento entre aquellos que optan por la convivencia de pareja sin pasar por los juzgados o la vicaría. Uno de los efectos de la prolongación de la soltería es la disminución en el número de personas jóvenes que son padres o madres. Sólo lo son en 1999 el 2,9\%. Desde hace varios años España tiene las tasas de natalidad más bajas de Europa: concretamente, entre el grupo de 20 a 24 años, se ha pasado de una tasa de fertilidad del 45,5\% en el año 90 a una de $23,3 \%$ en el 97.

La prolongación de la soltería y la no procreación de hijos por parte de la juventud española es una de las consecuencias más graves producidas por las dificultades que tiene este colectivo para alcanzar su emancipación y autonomía económica.

Como veíamos antes, al hablar de la dependencia de los jóvenes, uno de los datos más relevantes de la juventud española es el elevado número de jóvenes que residen con sus familias de origen. Desde el año 1987 hasta la fecha, los españoles de 20 a 24 años representan la proporción más numerosa de chicos europeos que aún viven con sus padres.

Pero al contrario de lo que se podría pensar, la prolongación de la permanencia juvenil en el hogar de los padres no se debe tanto a la voluntad de la juventud, como a la necesidad de hacerlo. La mayoría, si pudiese, optaría por emanciparse del domicilio familiar, tal y como se ve en los datos de la tabla siguiente, en el item "Lugar en el que elegirían vivir".

Para los españoles de 20 a 24 años, la edad media en la que un joven debe dejar el hogar paterno son los 24,5 años, aunque ellos no creen que lograrán su emancipación antes de los 26,3 años. Si se toma en cuenta que el principal motivo que lleva a los jóvenes a instalarse en su propia casa es el matrimonio, la edad de emancipación calculada 
Tabla 12. Lugar en el que elegirían vivir los jóvenes por edades.

\begin{tabular}{|c|c|c|c|c|c|}
\hline & Año & $\begin{array}{c}15 \text { a } 19 \\
\text { años }\end{array}$ & $\begin{array}{c}20 \text { a } 24 \\
\text { añ̃os }\end{array}$ & $\begin{array}{c}15 \text { a } 24 \\
\text { años }\end{array}$ & Fuente \\
\hline \multirow[t]{3}{*}{ viven con padres } & 1987 & - & 84. & - & Youth in the European Unión. Eurostat, 1997 \\
\hline & 1995 & - & 89. & - & Youth in the Earopean Unión. Eurostat, 1997 \\
\hline & 1998 & 98.6 & 85. & - & Juventudy Calidad de vida, 1998 INJUVE \\
\hline Lugar en el que elegirian vivir & 1999 & & & & Informe Juventud 2000. INJUVE \\
\hline - En casa de sus padres & & 39.3 & 21.0 & 29.9 & \\
\hline - En su propia casa (independiente) & & 37.1 & 67.7 & 51.8 & \\
\hline
\end{tabular}

Informe sobre España, Proyecto TSER(AREA), junio 2000.

por ellos se queda por debajo de las cifras reales: en el año 1995, la media nupcial para las mujeres fue de 27,4 y para los varones 29,8 .

Según ellos mismos, la razón principal de las prolongadas estancias de los hijos en la casa familiar es la falta de medios para instalarse solos. Coinciden en esa explicación con todos los estudios de juventud realizados en España, en donde ha quedado demostrado que la permanencia de los jóvenes en el hogar paterno se debe a las dificultades que tienen para conseguir un empleo estable.

Como ya hemos comentado, España tiene las tasas de paro más elevadas del entorno europeo. La precariedad en el empleo y la incertidumbre laboral aparece también como la causa principal de la disminución en la fecundidad de las mujeres jóvenes. Podemos afirmar que es falso que los jóvenes españoles no tengan hijos por comodidad o egoísmo.

La mayoría anhela tenerlos y cifra en dos el número de los que desearía, pero esa proporción disminuye cuando indican los que creen que en verdad llegarán a tener. La juventud es consciente que la disminución de la natalidad obedece a factores económicos y por ello las tres cuartas partes de los jóvenes consideran que el Estado debería tomar medidas para fomentar el que las parejas españolas puedan tener más hijos.

En relación a la evolución de las tasas de abortos, se observa un aumento ininterrumpido de los mismos, a lo largo de toda la década. La mayor incidencia se da entre las mujeres de 20 a 24 años. En este grupo de edad, el número de abortos supera, en todos los años, a los promedios nacionales.

En el caso de España, resulta falso el prejuicio de que la juventud actual no desea casarse por el rechazo a adquirir compromisos. En realidad, si tuvieran que optar por una convivencia de pareja, la mayo- 
Tabla 13. Opiniones de los jóvenes en relación a la fecundidad

\begin{tabular}{|c|c|c|c|c|c|}
\hline & Año & $\begin{array}{c}15 \text { a } 19 \\
\text { años }\end{array}$ & $\begin{array}{c}20 \text { a } 24 \\
\text { años }\end{array}$ & $\begin{array}{c}15 \text { a } 24 \\
\text { años }\end{array}$ & Fuente \\
\hline & & \multicolumn{4}{|c|}{ Varones Mujers } \\
\hline \multirow{2}{*}{$\begin{array}{l}\text { Año del primer matrimonio en } 1995 \\
\text { y diferencia con } / 1965\end{array}$} & 1965 & $\sum: 28.4$ & $\sum: 26.8$ & & Instituto Nacional de Estadística. \\
\hline & 1995 & $\sum: 29.8$ & $\sum: 27.4$ & & Mov. Natural de la Población Española \\
\hline \multirow[t]{2}{*}{ * Fertilidad porcentaje (x1000) } & 1990 & 9.2 & 45.5 & - & EUROSTAT,1999 \\
\hline & 1997 & 6.1 & 23. & - & EUROSTAT,1999 \\
\hline Tienen hijos & 1999 & .6 & 5.2 & 2.9 & Informe Juventud 2000. INJUVE \\
\hline $\mathrm{N}$. de hijos que desearían tener (medias) & 1997 & $\sum: 2.24$ & $\sum: 2.21$ & - & Juventud y Familia, 1997. INJUVE \\
\hline N. de hijos que llegarán a tener (medias) & 1997 & $\sum: 2.09$ & $\sum: 1.94$ & - & Juventudy Familia, 1997. INJUVE \\
\hline $\begin{array}{l}\text { Creen que el Estado debería tomar medidas } \\
\text { para que las parejas puedan tener un mayor } \\
\text { número de hijos }\end{array}$ & 1997 & 70.4 & 74.6 & - & Juventud y Familia, 1997. INJUVE \\
\hline
\end{tabular}

Informe sobre España, Proyecto TSER(AREA), junio 2000

ría elegiría un matrimonio legal, ya sea jurídico o eclesiástico.

El matrimonio sigue gozando de popularidad entre los jóvenes, quienes lo consideran como una institución muy importante que proporciona estabilidad a la pareja. Pero esa valoración no impide que la gran mayoría considere que las parejas de hecho deben de tener los mismos derechos legales, económicos y sociales que las casadas. Esa permisividad se ve reforzada por las altas proporciones de jóvenes que aseguran que se pueden imaginar a sí mismos viviendo en pareja sin estar casados.

Chicos y chicas manifiestan un fuerte arraigo afectivo y axiológico hacia la familia. Es una de las instituciones sociales que más valoran y está entre las cosas que para ellos son más importantes en la vida. La convivencia de los jóvenes españoles en sus hogares se basa en la armonía y, según ellos mismos, en la comprensión y tolerancia que sus padres les profesan (López Blasco, A. (1996) “Erzwungene Harmonie”).

En sus familias es más habitual que las decisiones que afectan a los hijos se tomen por consenso y no por autoritarismo, sobre todo cuando los chicos se van haciendo mayores. También parece existir entendimiento en lo que a visión del mundo se refiere. Padres e hijos están de acuerdo en muchos temas, salvo en los políticos y en los sexuales.

Con todo, la principal fuente de desacuerdo no está constituida por las ideas sino por las acciones y prácticas cotidianas (responsabilidades domésticas, horarios de entrada y salida de casa). 
Tabla 14. Opiniones de los jóvenes en relación a la nupcialidad

\begin{tabular}{|c|c|c|c|c|c|}
\hline & Aก̃̃o & $\begin{array}{c}15 \text { a } 19 \\
\text { años }\end{array}$ & $\begin{array}{c}20 \text { a } 24 \\
\text { años }\end{array}$ & $\begin{array}{c}15 \text { a } 24 \\
\text { años }\end{array}$ & Furgite \\
\hline Mejor forma de convivencia para una pareja estable & 1997 & & & & \multirow[t]{5}{*}{ Juventud y Familia, 1997. INJUVE } \\
\hline - Casarse por la Iglesia & & 39.7 & 33.7 & 一 & \\
\hline - Casarse por lo civil & & 3.6 & 5.7 & - & \\
\hline - Vivir juntos y luego casarse (Iglesia o Civil) & & 34.2 & 35.5 & - & \\
\hline - Vivir juntos sin estar casados & & 16.5 & 19.9 & - & \\
\hline $\begin{array}{l}\text { Opinión con la que se identifica respecto a las parejas } \\
\text { que viven juntas sin estar casadas }\end{array}$ & 1997 & & & & \multirow[t]{4}{*}{ Juventud y Familia, 1997. INJUVE } \\
\hline - Nunca lo haría y desaprueba que la gente lo haga & & 5.0 & 4.0 & - & \\
\hline - Nunca lo hatía pero acepto que otros lo hagan & & 39.1 & 32.2 & - & \\
\hline $\begin{array}{l}\text { - Me puedo imaginar a mí mismo viviendo en pareja } \\
\text { sincasarme }\end{array}$ & & 55.4 & 61.7 & - & \\
\hline $\begin{array}{l}\text { Acuerdo con que las parejas que viven juntas sin estar } \\
\text { casadas tengan los mismos derechos que los casados }\end{array}$ & 1997 & 82.5 & 85.4 & - & Juventud y Familia, 1997. INJUVE \\
\hline
\end{tabular}

Informe sobre España, Proyecto TSER(AREA), junio 2000.

Tabla 15. Opiniones de los jóvenes respecto a las relaciones familiares

\begin{tabular}{|l|c|c|c|c|l|}
\hline & Año & $\begin{array}{c}15 \text { a } 19 \\
\text { años }\end{array}$ & $\begin{array}{c}20 \text { a } 24 \\
\text { años }\end{array}$ & $\begin{array}{c}15 \text { a } 24 \\
\text { años }\end{array}$ & Fuente \\
\hline Consideran a sus padres "poco" estrictos: & 1997 & & & & Juventudy Familia, 1997. INJUVE \\
\hline -Al padre & & 39.3 & 44.9 & - & \\
\hline -A la madre & & 48.2 & 49.9 & - & \\
\hline \begin{tabular}{lllllll|} 
Formas que se toman en su familia las decisiones que \\
afectan a los hijos:
\end{tabular} & 1997 & & & & \multirow{2}{*}{ Juventud y Familia, 1997. INJUVE } \\
\hline Padres e hijos debaten, pero deciden los padres & & 34.0 & 28.0 & - & \\
\hline Padres e hijos debaten y llegan a un compromiso & & 45.4 & 52.8 & & \\
\hline Se encuentran muy satisfechos con su familia & 1997 & 97.4 & 96.6 & - & Juventudy Familia, 1997. INJUVE \\
\hline
\end{tabular}

Informe sobre España, Proyecto TSER (AREA), junio 2000.

\section{CONCLUSIONES Y PROPUESTAS}

La primera se refiere a la familia de origen y a los progenitores, la segunda a los propios jóvenes y a su futuro, y la tercera a la propia sociedad.

1. La primera cuestión responde a la pregunta de hasta cuándo podrá resistir la familia de origen la "carga" psicológica, económica y 
social que supone que los hijos alarguen su presencia en la familia. La familia, o mejor los padres/madres, viven la situación con un doble sentimiento. Por un lado y teniendo en cuenta la mentalidad de los actuales progenitores, educados en una época en que los roles de padre y madre y las funciones de la familia estaban organizadas en torno a la protección de sus miembros, a la realización en el caso de la mujer de su ser mujer a través de la maternidad y de la atención y cuidado a los miembros de la familia, ser ama de casa, la presencia de hijos hasta los 30 años y más supone alargar el sentido de la vida para la generación progenitora, pero al mismo tiempo y por otro lado es una fuente de preocupación para los padres porque no ven futuro a sus hijos y a veces porque el refugio familiar se convierte en un hotel con un buen servicio, y sin grandes costos para los hijos, quienes mantienen alto grado de libertad, y donde no necesitan asumir ninguna responsabilidad. Se convierten en "huéspedes de casa" con frecuencia a costas del (sobre-) esfuerzo de la madre y económicamente y socialmente del esfuerzo de todos.

Puede ser que la generación actual, que comparte todavía aunque sea fragmentalmente la concepción familiar que hemos descrito, y en la que las madres no trabajan fuera del hogar o lo hacen en un porcentaje menor, pero mientras tanto las madres de generaciones posteriores, con una nueva mentalidad por lo menos en parte y con tareas laborales fuera de la propia casa, no encuentre tan asimilable la presencia de jóvenes mayores en casa. Es verdad que todavía no hay movimientos sociales en este sentido, pero pueden aparecer en cualquier momento.

El que haya padres que abandonen su hogar para irse a otra vivienda dejando la propia a los hijos es un fenómeno ya observable, así como la intervención de tribunales para "obligar" a los hijos a abandonar el domicilio paterno-materno.

Las organizaciones de consumidores, y otras posibles organizaciones, pueden convertirse en catalizadores de los descontentos acumulados en las familias en los últimos años.

2. Para los propios jóvenes, la situación es soportable en tanto en cuanto que la familia se ha convertido en un refugio, en un lugar en la que experimentan la seguridad que no encuentran en los espacios sociales. Económicamente pueden vivir de los padres, aunque suponga un sacrificio para ellos.

Sin embargo su deseo de emancipación, su autoestima, su proyección y proyecto de futuro quedan mermados. Su dicotomía, de ser por un lado adulto, mayor de 18 años, responsable ante la ley incluso desde 
los 16 años, capaz y hábil para votar y codeterminar las políticas del país y de su Comunidad Autónoma, etc. Y por otro, permanecer "niño" en cuestiones tan importantes como la autonomía económica, la autovaloración y el autoconcepto a la larga puede generar en una aversión contra la sociedad, a desarrollar un resentimiento frente a ella, que puede ser canalizado por grupos ideológicamente cerrados, o por líderes sin escrúpulos o relegarse a una vida "hoy" en una posición de resignación, "mañana ya veremos" (lo que se ha denominado como presentismo, o vivir el presente).

La valoración tan alta que hacen de la familia y de las amistades más que un signo de tranquilidad para los responsables políticos y sociales debe ser más de preocupación. Los jóvenes perciben la familia como el único lugar seguro, ¿cómo no lo van a valorar?, pero al mismo tiempo esa valoración positiva no la transforman en un proyecto de creación de familia propia en autorresponsabilidad, lo desean, pero no lo realizan.

Al mismo tiempo constatamos la reversibilidad en las relaciones de pareja como un fenómeno fundamentalmente propio de los jóvenes. ¿Qué significa entonces que valoren positivamente la familia y las relaciones de pareja? No otra cosa que valorar la seguridad que momentáneamente les proporciona la familia y que les quita la ansiedad que produce la situación de inseguridad que caracteriza la sociedad de la información, la sociedad red, la sociedad de la globalización y de la individualización y del riesgo que se manifiesta y se detecta de una manera excepcionalmente sensible por los jóvenes. No sin motivo se ha considerado a la juventud el sismógrafo que detecta de un modo precoz y sensible los cambios, las transformaciones profundas que se están llevando a cabo, aunque aparezcan de manera silenciosa en la sociedad actual.

3. Como tercera cuestión se plantea la pregunta de ¿hasta dónde puede permitirse una sociedad vivir con una ruptura de las solidaridades intergeneracionales que suponen por un lado las ayudas a la integración social de los jóvenes, las nuevas generaciones y por otro asegurar a cada nuevo miembro de la sociedad su puesto, su sitio en ella? Esta "obligación" general se convierte en las democracias en la piedra de toque, en la piedra angular de su legitimidad y de su permanencia.

Por otro lado la sociedad tampoco puede "derrochar" recursos humanos. La juventud mejor preparada está al mismo tiempo condenada a mantener unas potencialidades sin explotar, y poniendo en peligro su propia continuidad, la de la sociedad, al no renovarse las generaciones.

Junto a las políticas de inmigración, que faciliten por un lado completar los déficits de población y asegurar la mano de obra para las 
actividades que no quiere realizar la población autóctona, la sociedad deberá incentivar la renovación generacional de su propia población.

Las políticas familiares desde la perspectiva de los jóvenes deben ir encaminadas a considerar a éstos como los potenciales creadores de familias del futuro, lo que sólo puede ser posible desde la creación de un espacio social de seguridad para los jóvenes. Acentuamos lo de social, pues paradójicamente a otros espacios como el educativo y el sanitario, por mencionar dos sistemas típicos del estado de bienestar, se han relegado al ámbito público y social. El empleo de los jóvenes se deja en manos de la ley de la oferta y de la demanda, de las familias, o a la suerte de cada uno, es decir, en el ámbito privado si no ya privatísimo. La adquisición de la vivienda para los jóvenes en un artículo de lujo para los más pudientes y para los pocos que han conseguido un trabajo estable, y la cría de la prole se deja en las manos del padre y/o madre.

Es decir, ante la vulnerabilidad de algunos sectores de la población entre ellos la de los jóvenes que supone una sociedad en transformación, en vez de aminorarla para aquellos que más la sufren, se deja a la autorregulación, de los mecanismos propios de esa sociedad en cambio, mientras que lo más correcto y tranquilizador sería asumir el riesgo desde las instancias sociales, prestando al individuo una "cierta sensación de pertenencia a un colectivo, a la sociedad", sustrayéndole de la situación de "solo ante el peligro". Sólo ella, la sociedad, en su conjunto puede dar seguridad a los colectivos más vulnerables.

Los jóvenes podrán conseguir su deseada emancipación real, emocional, económica, laboral, etc. y desarrollarán proyectos de futuro incluyendo la fundación de núcleos familiares en parejas, en matrimonios o monoparentalmente, cuando los costes no sean (sólo y fundamentalmente) individuales, los riesgos (p.e. para las madres de perder el tren de su carrera profesional o de sus competencias profesionales) no sean para los que aportan hijos a la sociedad, en definitiva cuando la familia, su apoyo, manutención y desarrollo se convierta en una cuestión social $\mathrm{y}$ los hijos en un activo social igualmente.

La creación de un espacio social de seguridad para los jóvenes supondría políticas transversales sociales y tendrían que ver con un refuerzo de los derechos individuales. Si un joven en edad escolar no va a la escuela, no se le encarga a la familia para que sustituya a la escuela, se le obliga, se le posibilita al joven a ir a la escuela en contra incluso de los intereses (¿legítimos?) de la propia familia.

Ni un joven sin formación, ni un joven sin ingresos (por trabajo o en su carencia a través de sistemas de protección social), ni un joven sin vivienda, ningún hijo/a sin subsidio independientemente de su vincula- 
ción a una familia, a un estatus social de sus padres o a una situación jurídica determinada de los mismos. Ninguna joven que pierda su futuro profesional por tener y criar prole.

\section{BIBLIOGRAFÍA}

AGUINAGA, J., COMAS, D. (1996): Cambios de hábito en el uso del tiempo. Madrid, INJUVE.

ALISCH, M., DANGSCHAT J.S.(1998): Armut und soziale Integration. Strategien sozialer Standentwicklung und lokaler Nachhaltigkeit. Opladen. Leske +Budrich.

ÁlVAREZ, R., AZAFRA, Ma J., CUESTA, M. (1997): Economía y Juventud. Madrid, INJUVE.

ANGULO URIBARRI, J.(1996): Vivienda joven de Europa. Vivienda y juventuden España. Madrid, INJUVE.

BECK, U.(1986): Risikogesellschaft. Auf dem Weg in eine andere Moderne. Frankfurt, M.edition suhrkamp.

BECK, U. (1999): Schöne neue Arbeitswelt., Vision.: Weltbürgergeseschaft. Frankfurt, M.edition suhrkamp.

BUCK, G. (1982): Gemeinwesenarbeit und kommunale Sozialplanung. Untersuchung zur sozialpolitischen Funktion und historischen Entwicklung eines Handlungsfeldes der sozialarbeit.Berlin, Hofgarten.

CASTELLS, M. (1997): La era de la información.Economia, sociedad y cultura.Vol l l La sociedad Red. Madrid, Alianza Editorial.

Centro de Investigaciones Sociológicas (CIS) (1996): Expectativas y preocupaciones sociales de los jóvenes. Madrid, CIS.

CRUZ CANTERO P., SANTIAGO GORDILLO, P. (1997): Juventud y entorno Familiar. Madrid, INJUVE.

DE MIGUEL, A. (2000): Dos generaciones de jóvenes 1960-1998. Madrid, INJUVE.

ESPING-ANDERSEN, G. (1993): Los tres mundos del estado de bienestar. Valencia, Edicions Alfons el Magnànim/IVEI.

FISCHER, A. y otros (2000): Jugend 2000. 13. Shell Jugendstudie. Opladen.Leske + Budrich.

GIARINI O., LIEDKE P.M.: Del dilema del Empleo. El futuro del trabajo. Galaxia Gutenberg. Informe del Club de Roma.

GIDDENS, A. (1994): Consecuencias de la modernidad. Madrid, Alianza.

GIDDENS, A. (1995): Modernidad e identidad del yo. El yo y la sociedad en la época contemporánea. Barcelona, Edic. Península. 
FRIEDLANDER, W. (1989): Dinámica del trabajo social. Pax-México. México. HAMBURGER, F. (1996): “Ámbitos de intervención socio-educativa y perspectivas para la educación permanente de adultos al cambio de siglo". En: Hernández A. J. y Lopez B.A. Madrid, MEC, pags. 47 y ss.

HERNÁNDEZ, J., LÓPEZ, A. (1995): "La familia en Navarra, individualización o redes sociales" Documentación Social. Revista de Estudios Sociales y Sociología Aplicada. Madrid, Cáritas Española, nº 98.

HERNÁNDEZ, J., LÓPEZ, A. (1995): Informe sobre la Familia en Navarra. Pamplona, Universidad Pública de Navarra.

IGLESIAS DE USSEL, J. (1995): "Familia" Documentación social. Revista de Estudios Sociales y Sociologia Aplic., $\mathrm{n}^{\circ}$ 101. Madrid, Cáritas Española.

INJUVE (1998): Juventud y calidad de vida. Madrid, INJUVE.

Instituto Navarro de Deporte y Juventud (1997): Jornadas de Juventud. Memoria. Pamplona, Gobierno de Navarra.

LÓPEZ,A., HERNÁNDEZ, J.,VISCARRET, J.J., CABASÉS, ERREA, J. (1999): Jovenes en una sociedad segmentada. Valencia, NAU llibres.

MACHADO PAÍS, J. (1997): "El futuro... ¿es de todos por igual o de unos más que de otros?. Culturas Juveniles, ocios, estilos de vida". En: YOUNIS, J.A. Ni diferentes ni indiferentes. Los jóvenes en el mundo de hoy. págs 111132. Maspalomas, Fundación Maspalomas. Universidad de verano de Maspalomas.

MARTÍN SERRANO, M. (1997): Juventudy Consumo. Madrid, Instituto Nacional de Consumo.

MARTÍN SERRANO, M. (1997):Informe Juventud en España. Madrid, INJUVE.

MARTÍN SERRANO, M. (2001):Informe. Juventud de España 2000. Madrid, INJUVE.

PÉREZ-DÍAZ,V.,CHULIÁ, E., ÁLVAREZ-MIRANDA, B. (1998): Familiay sistema de bienestar. La experiencia española con el paro, las pensiones, la sanidad y la educación. Madrid, Fundación Argentaria-Visor.

Revista De Juventud, $\mathrm{n}^{\circ}$ 39/ 1997. Monográfico sobre Juventud y familia.

TIMMERMANN, E. (1998): Das eigene Leben leben. Autobiographische Handlungskompetenz und Geschlecht. Opladen. Leske + Budrich.

VV.A.A.: Juventud en Navarra 98. Gobierno de Navarra. 